\title{
Who now believes in the neutron bomb?
}

The Reagan Administration, which has been promising clarity and decisiveness since it occupied Washington three weeks ago, has begun badly in its pronouncements on the neutron bomb. One day, there was Mr Caspar Weinberger, the Secretary of Defense, promising that plans to deploy what is called the neutron bomb in Europe would be dusted off and reconsidered. A few days later, last week, Mr Alexander Haig, conscious because of his long spell in Brussels of European susceptibilities on this point, was saying that no decision had yet been taken and that none would be without prior consultation with the European members of the North Atlantic Treaty Organization. People in Europe will recognize that they have been here before. It is only two years since President Carter twisted every arm in sight, persuaded most but not all members of the alliance to accept the notion that neutron bombs were a sensible part of the armoury of the West and then backed down at a point at which the West German government was in the thick of persuading a sceptical Bundestag that Mr Carter's first thoughts were right. Mr Haig is right to have spotted so quickly that the same battle cannot be fought a second time without spilling somebody's blood; perhaps he will make a good Secretary of State. Mr Weinberger's ruminations are understandable - a new man in an old post, discredited by too much vacillation, anxious to give the new Caesar comfort. They are not so easily forgivable.

The issue of the neutron bomb is more than merely a problem in military technology, but the technology is not irrelevant. Neutron bombs, when first described in outline three years ago, were held to have special military advantages. They could, the argument went, kill the crews of tanks whatever the thickness of the armour protecting them from the effects of conventional explosives. In principle, the argument is credible. The assumption must be that it is possible to generate neutrons from fusion explosions (the energy of fission neutrons is too little) without generating too much of the encumbering mechanical and thermal energy. Neutrons between ten and twenty million electron volts constitute a penetrating form of nuclear radiation. There is a good chance that an impinging neutron will penetrate the few inches of armour plating around a tank. The people inside, however, are more vulnerable. Consisting (as they do) largely of water, people function much like the moderating materials in nuclear reactors. They decelerate neutrons more efficiently than armour plating, chiefly because they have lighter atomic nuclei, but only by generating within themselves fast-moving and potentially damaging protons. The result is that people who think themselves protected by the vehicles they ride in will often be exposed to a fatal dose of radiation. In the macabre nature of these happenings, however, they will not always be aware of what has hit them. The first nausea may not come over them for half an hour or so and by then, of course, they may be dead from other causes as people on battlefields often discover to their cost.

Technically, the neutron bomb is therefore an exceedingly specialized weapon. It cannot be used on a battlefield as such, for its effects would be too slow. It is not, however, a strategic weapon. Yet the effects of a neutron bomb must be largely local. A hundred metres of atmosphere would probably have a stopping power for the spectrum of neutrons from a thermonuclear mixture not very different from a thin skin of armour plating. Thus pure neutron bombs cannot be used to attack targets spanning more than a few hundred metres on the ground without losing much of their power to do damage. On the other hand, they cannot be detonated near the ground without generating fallout. This, no doubt, is why most speculation on the subject has been concerned with the use of neutron bombs against concentrations of tanks marshalled for conventional attacks on some nearby target. By that means, the argument goes, it might be possible to prevent the tanks from rolling without so polluting the neighbourhood that everybody would be hurt. The scenario is appealing but not persuasive. Will generals saddled with the responsibility for using neutron bombs be able to make the delicate calculations of optimum detonation height that nuclear physics will require of them or their assistants? Will their opposite numbers in command of the hypothetical hostile tanks, having read in the newspapers of neutron bombs, then calmly assemble their forces in the manner appropriate to the Second World War? And, given the difficulty of arranging for public demonstrations, will either side in some future conflict take these drawing-board weapons seriously?

What Mr Haig to his credit appreciates is that there are more immediate problems. With the passage of time, it becomes more apparent that each new weapon requires a separate negotiation within the alliance which is the chief permanent commitment of the United States outside its borders. The wish to site cruise missiles in European states is still being talked about, and in some places (the Netherlands) may yet be talked out. The case for siting neutron bombs (Carter-style) in Europe took almost as long to make before President Carter listened more attentively than he need have done to what $\mathrm{Mr}$ Brezhnev had to say on the subject. In reality, the United States need not have made an issue of the neutron bomb and, more to the point, should not have done so. Cruise missiles raise novel issues, but neutron bombs are covered by the agreement within the North Atlantic Treaty Organization on the deployment of tactical nuclear weapons. If, as seems likely, they have only a specialized role to play in defence planning, and if the consequences of their use are likely to be less and not more serious, no new principle seems to be involved. In short, the issue of the neutron bomb seems less a consequence of improved technology in nuclear weapons than of President Carter's wish to say something publicly that had not been said before. $\mathrm{Mr}$ Weinberger appears to have fallen into the same trap.

Mr Haig's proposed remedy makes the best of a bad job. He promises that there will not now be a decision to site neutron bombs in Europe without full consultation with Western European governments. Given the history of the past few years, he has no other diplomatic choice. Mr Brezhnev should be pleased, but will refrain from saying so, even if he knows that his complaints at President Carter for seeking to deploy neutron bombs were partly bluff. (Neutron cross-sections are the same in the Soviet Union and the United States.) Mr Haig will no doubt also be pleased; he will have etablished his authority over the Department of Defense early in the new administration. Yet the problem of Europe remains to haunt him. Only three months after being returned to power, the West German coalition government is now less able to face a political battle about novel kinds of weapons than it was before the election last November. Other members of the alliance, the Netherlands for example, appear to have given up the internal struggle. None of this implies that NATO is about to fall apart but only that many of its members have become aware of the reality of the risk of conflict, and of the upheavals that may yet follow what is happening in Poland. Mr Haig must want to bring Western Europe up to scratch. Paradoxically, he may find that the only way to do that is to dust off not the neutron bomb but the series of arms control negotiations between East and West that have been in limbo since last September. 